\title{
Virulence Spectrum of Single-Spore and Field Isolates of Plasmodiophora brassicae Able to Overcome Resistance in Canola (Brassica napus)
}

\author{
Homa Askarian, Alireza Akhavan, Victor P. Manolii, Tiesen Cao, Sheau-Fang Hwang, and Stephen E. Strelkov ${ }^{\dagger}$ \\ Department of Agricultural, Food and Nutritional Science, University of Alberta, Edmonton, AB T6G 2P5, Canada
}

\begin{abstract}
Clubroot, caused by Plasmodiophora brassicae Woronin, is an important disease of canola (Brassica napus $\mathrm{L}$.) that is managed mainly by planting clubroot-resistant $(\mathrm{CR})$ cultivars. Field isolates of $P$. brassicae can be heterogeneous mixtures of various pathotypes, making assessments of the genetics of host-pathogen interactions challenging. Thirty-four single-spore isolates were obtained from nine field isolates of the pathogen collected from CR canola cultivars. The virulence patterns of the single-spore and field isolates were assessed on the 13 host genotypes of the Canadian Clubroot Differential (CCD) set, which includes the differentials of Williams and Somé et al. Indices of disease (IDs) severity of 25,33 , and $50 \%$ ( $\pm 95 \%$ confidence interval) were compared as potential thresholds to distinguish between resistant and susceptible reactions, with an ID of $50 \%$ giving the most consistent responses for pathotype

classification purposes. With this threshold, 13 pathotypes could be distinguished based on the CCD system, 7 on the differentials of Williams, and 3 on the hosts of Somé et al. The highest correlations were observed among virulence matrices generated using the three threshold IDs on the CCD set. Genetically homogeneous single-spore isolates gave a clearer profile of the $P$. brassicae pathotype structure. Novel pathotypes, not reported in Canada previously, were identified among the isolates. This large collection of single-spore isolates can serve as a reference in screening and breeding for clubroot resistance.

Keywords: Brassica napus, clubroot, field crops, fungi, oilseeds and legumes, pathogen diversity, pathotypes, Plasmodiophora brassicae, techniques
\end{abstract}

Clubroot, caused by the obligate parasite Plasmodiophora brassicae Woronin, is one of the most significant soilborne diseases of the Brassicaceae family (Dixon 2009a; Karling 1968). On infected plants, $P$. brassicae causes the malformation of the tap and lateral roots, resulting in the development of clubs or galls that are the most characteristic symptom of the disease (Kageyama and Asano 2009; Voorrips 1995). As root galling becomes more severe, the uptake of water and nutrients is reduced and affected plants may wilt, even under moderate moisture stress. Severe infections result in stunting, premature plant senescence, accelerated flowering, and, ultimately, major yield losses (Dixon 2009a; Voorrips 1995). In Canada, clubroot has been a constraint to the production of brassica vegetables for over a century (Howard et al. 2010) but the disease was not identified on canola (Brassica napus L.) in the Prairies region until 2003, when it was found in 12 fields in central Alberta (Tewari et al. 2005). By 2018, clubroot infestations had been confirmed in $>3,000$ fields throughout Alberta (Strelkov et al. 2019), with additional infestations reported in Saskatchewan, Manitoba, and North Dakota. Clubroot can cause yield losses of 30 to $100 \%$ in susceptible canola (Strelkov and Hwang 2014) and poses a major threat to the production of this important crop (Rempel et al. 2014). The most effective clubroot management strategy is the deployment of genetically resistant cultivars (Diederichsen et al. 2009; Hirai 2006; Peng et al. 2014), which

${ }^{\dagger}$ Corresponding author: S. E. Strelkov; strelkov@ualberta.ca

Funding: Financial support was provided through Growing Forward 2, the Canadian Agricultural Partnership program (Agriculture and Agri-Food Canada and the Canola Council of Canada), and Alberta Canola. In-kind support was provided by the University of Alberta and Alberta Agriculture and Forestry. H. Askarian was the recipient of an award from The Storkan-HanesMcCaslin Foundation in support of some of her studies.

*The $\boldsymbol{e}$-Xtra logo stands for "electronic extra" and indicates that supplementary materials are published online.

The author(s) declare no conflict of interest.

Accepted for publication 25 June 2020.

(C) 2021 The American Phytopathological Society relies on an understanding of the virulence spectrum of $P$. brassicae populations. The occurrence of physiologic specialization is well documented in the clubroot pathogen, with multiple races or pathotypes identified based on their virulence patterns on various sets of differential hosts (Ayers 1957; Buczacki et al. 1975; Kuginuki et al. 1999; Somé et al. 1996; Strelkov et al. 2018; Williams 1966).

The prudent selection of differential host genotypes is important for the accurate identification of virulence phenotypes in specific regions (Somé et al. 1996; Strelkov et al. 2007). In Canada, the differentials of Williams (1966) have been used most commonly to characterize $P$. brassicae populations, although other systems, including the European Clubroot Differential (ECD) set (Buczacki et al. 1975) and the hosts of Somé et al. (1996), also have been employed occasionally. Although these differential sets have been fairly effective for detecting the predominant pathotypes of $P$. brassicae in Canada, each has its own limitations in the context of canola cropping systems (Strelkov and Hwang 2014). Most importantly, these systems do not distinguish between those strains of $P$. brassicae that can overcome the resistance in clubroot-resistant (CR) canola cultivars and those that cannot. Given the recent emergence of $P$. brassicae strains able to overcome resistance (Strelkov et al. 2016), a new set of differential hosts, the Canadian Clubroot Differential (CCD) set, was proposed to characterize $P$. brassicae populations (Strelkov et al. 2018). This system includes the differentials of Williams (1966), Somé et al. (1996), and selected hosts of the ECD set, as well as several B. napus hosts with differential resistance profiles. The inclusion of hosts from other systems, especially those of Williams (1966) and Somé et al. (1996), allows rapid comparisons of pathotype designations among systems.

A challenge for the identification of $P$. brassicae pathotypes is the intermediate and fluctuating disease reactions often observed on many of the differential hosts (Jones et al. 1982a; Scott 1985; Strelkov et al. 2006, 2007; Tinggal and Webster 1981; Toxopeus et al. 1986; Xue et al. 2008). These reactions may reflect heterogeneity and potentially quantitative resistance in some of the hosts but may also indicate heterogeneity in $P$. brassicae field isolates (Scott 1985; Somé et al. 1996; Tinggal and Webster 1981; Xue et al. 2008). Most studies on the virulence of $P$. brassicae have examined field isolates (synonym: field populations), which represent a collection of pathogen resting spores originally made from a single root gall 
or plant. Although field isolates are straightforward to obtain and propagate, they often represent a heterogeneous mix of pathotypes that can proliferate selectively on resistant host genotypes. Therefore, pathotypes found at lower frequencies within a field isolate may be masked by the presence of other pathotypes found at higher frequencies (Jones et al. 1982b). In addition, competition between virulent and avirulent pathotypes for infection sites or the effect of avirulent pathotypes on host resistance may complicate the interpretation of results obtained with $P$. brassicae field isolates (Jones et al. 1982b; Voorrips 1996).

The use of $P$. brassicae single-spore isolates in studies of clubroot may improve the consistency of host reactions and reflect true virulence patterns present in pathogen populations. The objectives of this study were to obtain single-spore isolates of the clubroot pathogen from field isolates virulent on CR canola, and to investigate the virulence diversity within and between field isolates that overcome host resistance. Different thresholds of disease severity were also compared in order to distinguish between susceptible and resistant reactions in those hosts that still gave intermediate reactions.

\section{Materials and Methods}

Clubbed root materials. The galled roots originated from nine commercial fields (Fig. 1) sown to CR canola cultivars (74-47 CR, 45H29, 74-54 RR, L135 C, or 1960) with a relatively high incidence of clubroot (Table 1). Seven of the fields were located in central Alberta, at the center of the clubroot outbreak (one field each from of the City of Edmonton and Red Deer and Leduc Counties, and two fields each from Sturgeon and Westlock Counties), another was located in northern Alberta (Athabasca County), and the ninth field was in southern Alberta (Newell County). The samples were collected during a clubroot survey conducted in 2014 (Strelkov et al. 2015), air dried at room temperature, and stored at $4^{\circ} \mathrm{C}$ in a cold room.

Single-spore isolation. Single-spore isolates were produced by a combination of the methods of Manzanares-Dauleux et al. (1994) and Xue et al. (2008), with several modifications. One dried gall was selected randomly from each field and placed in a 50-ml Falcon conical centrifuge tube (Fisher Scientific, Rochester, NY, U.S.A.) containing $20 \mathrm{ml}$ cold sterile distilled (SD) water. The gall was softened by incubating it in the SD water for $1 \mathrm{~h}$ at $4^{\circ} \mathrm{C}$, washed several times as necessary to remove any surface soil or debris, and then homogenized in SD water with a sterile mortar and pestle. The homogenate was filtered through 10 layers of cheesecloth (American Fiber $\&$ Finishing Inc., Albemarle, NC, U.S.A.). The resting-spore concentration in the filtrate was quantified with a hemocytometer (VWR, Mississauga, ON, Canada) and the final concentration was adjusted to 100 spores $/ \mathrm{ml}$ by adding sterile $5 \%$ glycerol. This stock was used to isolate individual resting spores via inoculation of 50 5-day-old Chinese cabbage (Brassica rapa L. var. pekinensis 'Granaat') seedlings, which had been germinated on moistened sterile filter paper in 9-cm-diameter Petri dishes. Briefly, the rootlets of each seedling were placed with tweezers on a coverslip inside a 6 -cm-diameter
Petri dish containing two pieces of sterile, moistened filter paper and put aside for subsequent use. Six square slices (approximately $1 \mathrm{~mm}^{2}$ each) of a $1 \%$ agarose gel were excised with a scalpel and placed on a microscope slide (disinfected with $70 \%$ ethanol), with $0.5 \mu \mathrm{l}$ of the spore suspension added to the center of each gel slice. After $1 \mathrm{~min}$, the slices were examined under a light microscope at $\times 400$ magnification. This procedure was repeated until 50 slices each, containing one round (approximately $4 \mu \mathrm{m}$ in diameter), robust, and intact resting spore, which was considered potentially mature and viable, had been obtained from each field isolate.

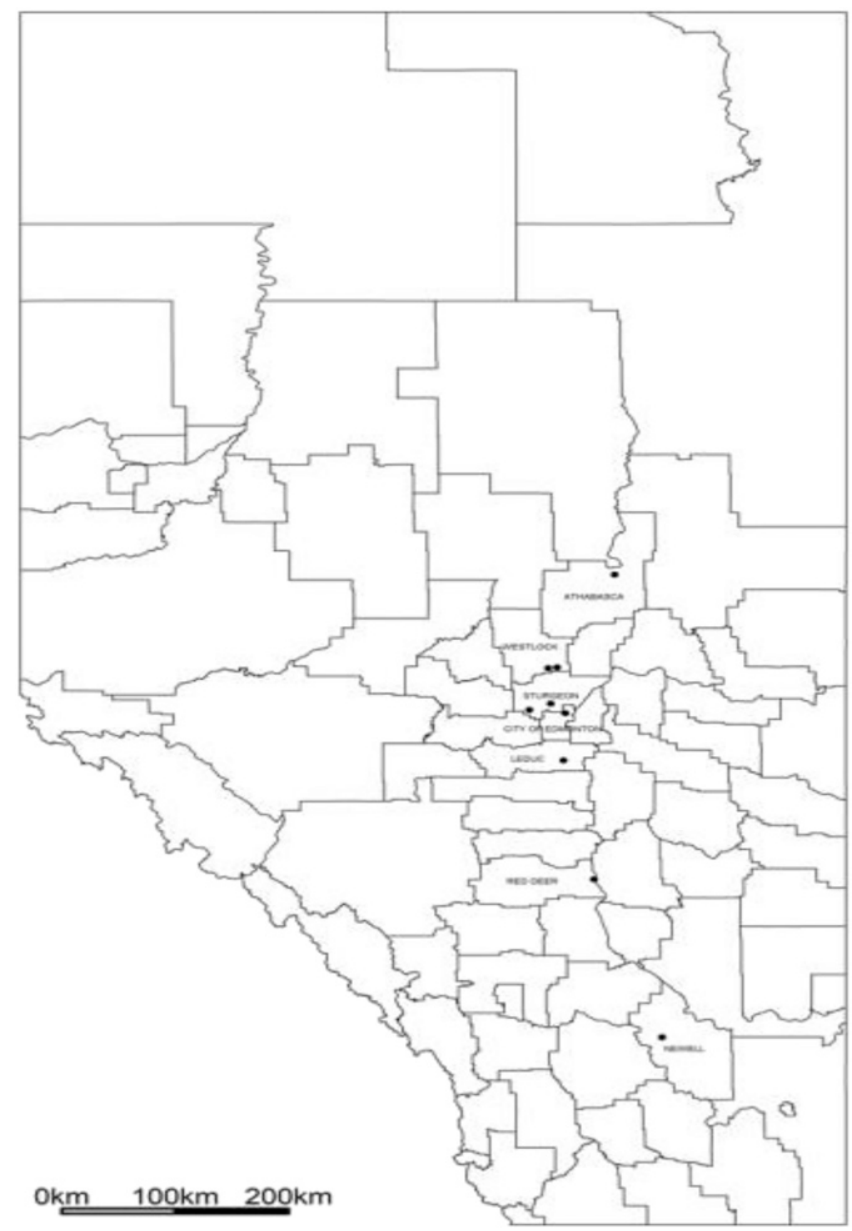

Fig. 1. Map of Alberta, Canada, showing the distribution of fields from which field and single-spore isolates of Plasmodiophora brassicae were collected for the current study.

Table 1. Origin of Plasmodiophora brassicae field isolates included in the current study ${ }^{\mathrm{a}}$

\begin{tabular}{llll}
\hline Field identification $^{\mathbf{b}}$ & Field isolate & \multicolumn{1}{c}{ Location } & \multicolumn{1}{c}{ Original host $^{\mathbf{c}}$} \\
\hline F1-14 & $1-14-\mathrm{P}$ & City of Edmonton & $74-47$ CR \\
CDCN\#4 & $4-14-\mathrm{P}$ & Westlock & L135 C \\
CDCN\#6 & $6-14-\mathrm{P}$ & Westlock & L135 C \\
F41-14 & $41-14-\mathrm{P}$ & Red Deer & $45 \mathrm{H} 29$ \\
F175-14 & $175-14-\mathrm{P}$ & Athabasca & $74-54 \mathrm{RR}$ \\
F183-14 & $183-14-\mathrm{P}$ & Sturgeon & L135 C \\
F187-14 & $187-14-\mathrm{P}$ & Sturgeon & $45 \mathrm{H} 29$ \\
CDCS & $290-14-\mathrm{P}$ & Newell & $45 \mathrm{H} 29, \mathrm{~L} 135 \mathrm{C}, 74-47$ CR, 1960 \\
F331-14 & $331-14-\mathrm{P}$ & Leduc & L135 C \\
\hline
\end{tabular}

a All of the field isolates were collected from clubroot-resistant (CR) canola crops in Alberta in 2014.

b Field identifications as designated by Strelkov et al. (2018).

c Cultivars of canola (Brassica napus) which were regarded as resistant to all field and single-spore isolates of $P$. brassicae collected before 2013 (Strelkov et al. 2016). 
Each agarose slice was then taken from the microscope slide with an insect pin and carefully placed on the root hairs of an individual Chinese cabbage seedling, which had been previously placed in a 6-cm-diameter Petri dish as described above. One drop of SD water was placed near the gel slice. The Petri dishes were wrapped with clear plastic food wrap (Clorox, Canada) and incubated in darkness at $23^{\circ} \mathrm{C}$ for $72 \mathrm{~h}$. Subsequently, each inoculated seedling was transferred to a small plastic pot $(6.5$ by 6.5 by $9 \mathrm{~cm})$ containing moistened potting mix (Sunshine Mix LA7; Sunshine Growers) and incubated for 8 weeks in a greenhouse maintained at about 24 and $18^{\circ} \mathrm{C}$ day and night, respectively, under natural light supplemented with artificial lighting (16-h photoperiod). The potting mix was kept saturated for 6 weeks by soaking the pots separately in water; over the remaining 2 weeks, the plants were watered as required and fertilized once a week. Great care was taken throughout all of the steps to avoid crosscontamination between isolates. The stock spore suspensions from which the single-spore isolations were made was retained and used as inoculum to propagate the original field isolates on Chinese cabbage Granaat and on the same resistant cultivar from which each field isolate was initially recovered.

Propagation of single-spore isolates. The inoculated plants were removed carefully from the potting mix and inspected for the presence of root galls. If a gall was observed, it was sectioned in two: one half was stored at $-20^{\circ} \mathrm{C}$ while the other half was homogenized in a mortar and pestle as above. The homogenate was filtered through four layers of cheesecloth and the resting-spore concentration was quantified with a hemocytometer and adjusted to $10^{7}$ spores $/ \mathrm{ml}$ in SD water. Seven-day-old Chinese cabbage Granaat seedlings (140 per resting-spore suspension) were inoculated by the root dip method (Strelkov et al. 2006), planted in potting mix, and grown in a greenhouse as above, except that the potting mix was kept saturated for 2 weeks and the roots were harvested after 6 weeks. The galls were washed in SD water and stored at $-20^{\circ} \mathrm{C}$ until further processing.

Pathotype classification. The virulence patterns of the field and single-spore isolates were assessed on the 13 host genotypes (Table 2) of the CCD set (Strelkov et al. 2018), which include the differentials of Williams (1966) and Somé et al. (1996). Inoculations were conducted following Strelkov et al. (2006), with $20 \mathrm{~g}$ of galls representing each field isolate or putative single-spore isolate. The inoculated seedlings were grown for 6 weeks in the greenhouse under the conditions described above, with the potting mix kept saturated with water for the first 2 weeks after inoculation. Experiments were conducted with four replicates for each host genotype-pathogen isolate combination and 12 plants per replicate (experimental unit); treatments were arranged in a split-plot design, with isolates as main plots and differential hosts as subplots. One single-spore isolate of each pathotype identified was selected and retested on the differentials an additional three times.

In the original description of the CCD set (Strelkov et al. 2018), isolates of $P$. brassicae with unique virulence patterns were assigned a letter (A, B, C, and so on) to denote different pathotypes. Each isolate could also be assigned a pathotype number based on the system of Williams (1966) and, although the two designations were often used together (e.g., pathotype 5X), they were not formally linked. Given the identification of multiple novel pathotypes in this report (see below), and following consultation among Canadian clubroot workers, the nomenclature for new pathotypes of $P$. brassicae has been modified slightly. In this and subsequent articles, the official pathotype designation will indicate the Williams number first, followed by a letter denoting the CCD designation. Although, previously, a letter was used only once and assigned independently of the Williams designation, now the entire alphabet may be applied to distinguish multiple variants of a single Williams pathotype (e.g., pathotype 3A, 3B, 3C). In order to avoid confusion, the designations for pathotypes that have already been published (Strelkov et al. 2018), such as 3A, 3H, and 5X, will be retained, with new letters used to denote new variants.

Disease assessment. Seedlings were uprooted 6 weeks after inoculation, and the roots were washed with water and evaluated for clubroot symptom development. Each root was rated on a 0-to-3 clubroot severity scale (Kuginuki et al. 1999), where $0=$ no galling, $1=$ a few small galls, $2=$ moderate galling, and $3=$ severe galling. An index of disease (ID) severity was calculated for each replicate based on the formula of Horiuchi and Hori (1980) as modified by Strelkov et al. (2006):

$$
\begin{aligned}
\mathrm{ID}(\%)=\{ & {[\Sigma(n \times 0)+(n \times 1)+(n \times 2)+} \\
& (n \times 3)] / N \times 3\} \times 100
\end{aligned}
$$

where $n$ is the number of plants in each class, $N$ is the total number of plants, and 0,1,2 and 3 are the symptom severity classes.

Analysis. For each host genotype-pathogen combination, mean IDs and 95\% confidence intervals (CIs) were calculated with Microsoft Excel 2016. Three thresholds were compared for the classification of resistant and susceptible reactions: ID $<50 \%$ (hosts classified as resistant if ID $<50 \%$ and the $95 \%$ CI does not overlap $50 \%$ ) (LeBoldus et al. 2012); ID < 33\% (host classified as resistant if ID $<33 \%$ and the $95 \%$ CI does not overlap 33\%), and ID < 25\% (host reaction classified as resistant if ID $<25 \%$ and $95 \%$ CI does not overlap 25\%). Each field and single-spore isolate was then classified into pathotypes based on their virulence patterns on the differential hosts (CCD, Williams, and Somé et al.).

Data were also converted into a 0-1 matrix, with 0 as resistant and 1 as susceptible, to generate a similarity matrix with NTSys-pc v 2.2 (Exeter Software, New York, NY, U.S.A.). The similarity matrix was then subjected to cluster analysis by the unweighted pair-group method of arithmetic means (UPGMA) and simple similarity coefficient. The UPGMA analysis was conducted with the SAHN program of NTSys-pc and dendrograms were generated using the Tree Plot program of the same software package (Akhavan et al. 2016). The Mantel test was used to calculate the correlation between the virulence matrices generated with threshold IDs of 25,33 , and $50 \%$ on the hosts of each of the three differential sets, using the MXCOMP program in NTSys-pc v. 2.2q with 999 permutations (Rohlf 2009).

\section{Results}

Single-spore isolation. In total, 450 Chinese cabbage Granaat seedlings were inoculated with single resting spores of $P$. brassicae representing nine "mother" field isolates. Each infected plant was assumed to represent a single-spore isolate. The severity of root infection was scored as 1,2 , or 3 , with a rating of 3 found to be the most

Table 2. Host genotypes included in the Canadian Clubroot Differential

\begin{tabular}{|c|c|}
\hline Host genotype $^{a}$ & Differential \\
\hline $\begin{array}{l}\text { ECD } 02 \text { (Brassica rapa subsp. rapifera } \\
\text { line AAbbCC) }\end{array}$ & $\mathrm{CCD}$ \\
\hline ECD 05 (B. rapa var. pekinensis 'Granaat') & CCD \\
\hline ECD 06 (B. napus var. napus 'Nevin’) & CCD, Somé et al. \\
\hline $\begin{array}{l}\text { ECD } 08 \text { (B. napus var. napus 'Giant Rape' } \\
\text { selection) }\end{array}$ & $\mathrm{CCD}$ \\
\hline $\begin{array}{l}\text { ECD } 09 \text { (B. napus var. napus New Zealand } \\
\text { resistant rape) }\end{array}$ & CCD \\
\hline $\begin{array}{l}\text { ECD } 10 \text { (B. napus var. napus } \\
\text { 'Wilmesburger') }\end{array}$ & CCD, Somé et al., Williams \\
\hline $\begin{array}{l}\text { ECD } 11 \text { (B. oleracea var. capitata } \\
\text { 'Badger Shipper') }\end{array}$ & CCD, Williams \\
\hline $\begin{array}{l}\text { ECD } 13 \text { (B. oleracea var. capitata } \\
\text { 'Jersey Queen') }\end{array}$ & CCD, Williams \\
\hline Laurentian (B. napus var. napobrassica) & CCD, Williams \\
\hline Brutor (B. napus) & CCD, Somé et al. \\
\hline Mendel (B. napus) & $\mathrm{CCD}$ \\
\hline 45H29 (B. napus) & $\mathrm{CCD}$ \\
\hline Westar (B. napus) & $\mathrm{CCD}$ \\
\hline
\end{tabular}
(CCD) set (Strelkov et al. 2018)

a The CCD set includes the differentials of Williams (1966), Somé et al. (1996), an additional four genotypes from the European Clubroot Differential (ECD) set (Buczacki et al. 1975), the clubroot-resistant (CR) winter oilseed rape Mendel, the open-pollinated spring canola Westar, and the CR hybrid canola $45 \mathrm{H} 29$. 
common reaction type (65\%). The infection rate varied from 2 to $22 \%$, with an average of $7.6 \%$ for inoculations with single-spore isolates derived from different field isolates. The highest infection rate $(22 \%)$ was obtained with resting spores derived from field isolate 187-14-P, followed by inoculations with resting spores from the field isolates 183-14-P (14\%) and 1-14-P (10\%). Three plants (6\%) with clubroot symptoms were obtained following inoculation with spores from each of the field isolates 41-14-P and 331-14-P. Two plants (4\%) developed symptoms following inoculation with resting spores derived from 4-14-P. Only 1 of 50 (2\%) seedlings inoculated with spores from each of the field isolates 6-14-P, 175-14-P, and 29014-P developed galls. Thirty-four single-spore isolates, representing nine field isolates, were recovered from the 450 inoculated seedlings (Table 3).

Isolate virulence and host reactions. The mean ID and lower and upper limits of the associated $95 \%$ CI for each host genotype and pathogen combination are summarized in Supplementary Table S1. All single-spore and field isolates were highly virulent (IDs of 92 to $100 \%$ ) on ECD 05, the universal susceptible host, and on the spring oilseed rape Brutor (IDs of 73 to $100 \%$ ). All but one isolate were highly virulent on the spring canola Westar (IDs of 79 to $100 \%$ ), with only the single-spore isolate 290-14-SS 1 causing low levels of disease (ID $=8 \%$ ). Similarly, all singlespore and field isolates, with the exception of 290-14-SS1, were virulent on the differential ECD 08 (IDs of 75 to 100\%). In contrast, the $B$. rapa genotype ECD 02 was highly resistant to all of the isolates tested (IDs of 0 to $9 \%$ ), developing little to no symptoms of clubroot. The B. napus hosts ECD 06, ECD 09, ECD 10, Laurentian, Mendel, and 45H29, and B. oleracea hosts ECD 11 and ECD 13, varied in their responses to specific field and single-spore isolates, and were able to differentiate pathotypes of $P$. brassicae.

The UPGMA cluster analysis using the simple similarity coefficient and a threshold ID of $25 \%$ to distinguish resistant versus susceptible reactions resulted in 4,8 , and 18 pathotype groups among the single-spore and field isolates tested on the differential sets of

Table 3. Efficiency of single-spore isolation and summary of pathotype designation of Plasmodiophora brassicae field isolates and their single-spore isolates

\begin{tabular}{|c|c|c|c|c|c|c|}
\hline \multirow{2}{*}{$\frac{\text { Isolates }}{\text { Field, single-spore }}$} & \multicolumn{2}{|c|}{ Number of plants } & \multirow[b]{2}{*}{ Infection rate $(\%)$} & \multicolumn{3}{|c|}{ Pathotype $^{\mathrm{a}}$} \\
\hline & Inoculated & Infected & & Somé et al. & Williams & CCD set \\
\hline $1-14-\mathrm{P}$ & 50 & 5 & 10 & $\mathrm{P}_{2}$ & 3 & $3 \mathrm{D}$ \\
\hline 1-14-SS1 & $\ldots$ & $\ldots$ & $\ldots$ & $\mathrm{P}_{2}$ & 2 & $2 \mathrm{~F}$ \\
\hline 1-14-SS2 & $\ldots$ & $\ldots$ & $\ldots$ & $\mathrm{P}_{3}$ & 6 & $6 \mathrm{~A}$ \\
\hline $1-14-S S 3$ & $\ldots$ & $\ldots$ & $\ldots$ & $\mathrm{P}_{2}$ & 3 & $3 \mathrm{H}$ \\
\hline $1-14-S S 4$ & $\ldots$ & $\ldots$ & $\ldots$ & $\mathrm{P}_{2}$ & 2 & $2 \mathrm{~F}$ \\
\hline 1-14-SS5 & $\ldots$ & $\ldots$ & $\ldots$ & $\mathrm{P}_{2}$ & 3 & $3 \mathrm{H}$ \\
\hline 4-14-P & 50 & 2 & 4 & $\mathrm{P}_{3}$ & 6 & $6 \mathrm{~B}$ \\
\hline 4-14-SS1 & $\ldots$ & $\ldots$ & $\ldots$ & $\mathrm{P}_{2}$ & 3 & $3 \mathrm{H}$ \\
\hline 4-14-SS2 & $\ldots$ & $\ldots$ & $\ldots$ & $\mathrm{P}_{3}$ & 6 & $6 \mathrm{~B}$ \\
\hline 6-14-P & 50 & 1 & 2 & $\mathrm{P}_{3}$ & 6 & $6 \mathrm{~B}$ \\
\hline 6-14-SS1 & $\ldots$ & $\ldots$ & $\ldots$ & $\mathrm{P}_{2}$ & 3 & $3 \mathrm{D}$ \\
\hline 41-14-P & 50 & 3 & 6 & $\mathrm{P}_{2}$ & 3 & $3 \mathrm{D}$ \\
\hline 41-14-SS1 & $\ldots$ & $\ldots$ & $\ldots$ & $\mathrm{P}_{2}$ & 3 & $3 \mathrm{H}$ \\
\hline 41-14-SS2 & $\ldots$ & $\ldots$ & $\ldots$ & $\mathrm{P}_{3}$ & 6 & $6 \mathrm{~B}$ \\
\hline 41-14-SS3 & $\ldots$ & $\ldots$ & $\ldots$ & $\mathrm{P}_{2}$ & 3 & $3 \mathrm{H}$ \\
\hline 175-14-P & 50 & 1 & 2 & $\mathrm{P}_{2}$ & 3 & $3 \mathrm{D}$ \\
\hline 175-14-SS1 & $\ldots$ & $\ldots$ & $\ldots$ & $\mathrm{P}_{3}$ & 6 & $6 \mathrm{C}$ \\
\hline 183-14-P & 50 & 7 & 14 & $\mathrm{P}_{2}$ & 8 & $8 \mathrm{E}$ \\
\hline 183-14-SS1 & $\ldots$ & $\ldots$ & $\ldots$ & $\mathrm{P}_{2}$ & 2 & $2 \mathrm{~A}$ \\
\hline 183-14-SS2 & $\ldots$ & $\ldots$ & $\ldots$ & $\mathrm{P}_{2}$ & 3 & $3 \mathrm{D}$ \\
\hline $183-14-S S 3$ & $\ldots$ & $\ldots$ & $\ldots$ & $\mathrm{P}_{2}$ & 2 & $2 \mathrm{~A}$ \\
\hline 183-14-SS4 & $\ldots$ & $\ldots$ & $\ldots$ & $\mathrm{P}_{1}$ & 4 & $4 \mathrm{~A}$ \\
\hline 183-14-SS5 & $\ldots$ & $\ldots$ & $\ldots$ & $\mathrm{P}_{3}$ & 6 & $6 \mathrm{~B}$ \\
\hline 183-14-SS6 & $\ldots$ & $\ldots$ & $\ldots$ & $\mathrm{P}_{2}$ & 3 & $3 \mathrm{D}$ \\
\hline 183-14-SS7 & $\ldots$ & $\ldots$ & $\ldots$ & $\mathrm{P}_{2}$ & 3 & $3 \mathrm{H}$ \\
\hline 187-14-P & 50 & 11 & 22 & $\mathrm{P}_{2}$ & 3 & $3 \mathrm{~A}$ \\
\hline 187-14-SS1 & $\ldots$ & $\ldots$ & $\ldots$ & $\mathrm{P}_{3}$ & 5 & $5 X$ \\
\hline $187-14-S S 2$ & $\ldots$ & $\ldots$ & $\ldots$ & $\mathrm{P}_{3}$ & 5 & $5 X$ \\
\hline 187-14-SS3 & $\ldots$ & $\ldots$ & $\ldots$ & $\mathrm{P}_{3}$ & 5 & $5 X$ \\
\hline 187-14-SS4 & $\ldots$ & $\ldots$ & $\ldots$ & $\mathrm{P}_{3}$ & 5 & $5 X$ \\
\hline 187-14-SS5 & $\ldots$ & $\ldots$ & $\ldots$ & $\mathrm{P}_{3}$ & 6 & $6 \mathrm{~B}$ \\
\hline 187-14-SS6 & $\ldots$ & $\ldots$ & $\ldots$ & $\mathrm{P}_{3}$ & 6 & $6 \mathrm{~B}$ \\
\hline 187-14-SS7 & $\ldots$ & $\ldots$ & $\ldots$ & $\mathrm{P}_{2}$ & 3 & $3 \mathrm{H}$ \\
\hline 187-14-SS8 & $\ldots$ & $\ldots$ & $\ldots$ & $\mathrm{P}_{3}$ & 6 & $6 \mathrm{~B}$ \\
\hline 187-14-SS9 & $\ldots$ & $\ldots$ & $\ldots$ & $\mathrm{P}_{2}$ & 3 & $3 \mathrm{H}$ \\
\hline 187-14-SS10 & $\ldots$ & $\ldots$ & $\ldots$ & $\mathrm{P}_{2}$ & 3 & $3 \mathrm{~A}$ \\
\hline 187-14-SS11 & $\ldots$ & $\ldots$ & $\ldots$ & $\mathrm{P}_{3}$ & 6 & $6 \mathrm{~B}$ \\
\hline 290-14-P & 50 & 1 & 2 & $\mathrm{P}_{3}$ & 6 & $6 \mathrm{~B}$ \\
\hline 290-14-SS1 & $\ldots$ & $\ldots$ & $\ldots$ & $\mathrm{P}_{2}$ & 7 & $7 \mathrm{~A}$ \\
\hline 331-14-P & 50 & 3 & 6 & $\mathrm{P}_{3}$ & 5 & $5 \mathrm{G}$ \\
\hline 331-14-SS1 & $\ldots$ & $\ldots$ & $\ldots$ & $\mathrm{P}_{2}$ & 3 & $3 \mathrm{H}$ \\
\hline $331-14-S S 2$ & $\ldots$ & $\ldots$ & $\ldots$ & $\mathrm{P}_{2}$ & 2 & $2 \mathrm{~F}$ \\
\hline 331-14-SS3 & $\ldots$ & $\ldots$ & $\ldots$ & $\mathrm{P}_{2}$ & 3 & $3 \mathrm{D}$ \\
\hline
\end{tabular}

${ }^{a}$ Each field and single-spore isolate was classified into pathotypes based on their virulence patterns on the differential hosts of the Canadian Clubroot Differential (CCD) set (Strelkov et al. 2018), Williams (1966), and Somé et al. (1996). A threshold index of disease (ID) of 50\% was considered to distinguish resistant versus susceptible reactions, with hosts classified as resistant if ID < 50\% and the 95\% confidence interval does not overlap 50\% (LeBoldus et al. 2012). 
Somé et al., Williams, and the CCD, respectively (Supplementary Fig. S1). In contrast, at a threshold ID of $33 \%, 4,9$, and 20 pathotype groups were obtained on each differential set, respectively (Supplementary Fig. S2). A threshold ID of 50\% resulted in 3, 7, and 13 pathotype groups on the differential sets of Somé et al. (Fig. 2), Williams (Fig. 3), and the CCD (Fig. 4), respectively.

The percentage of isolates scored as virulent on ECD $05(100 \%)$, Brutor (100\%), and Westar (98\%) was similar with all three threshold

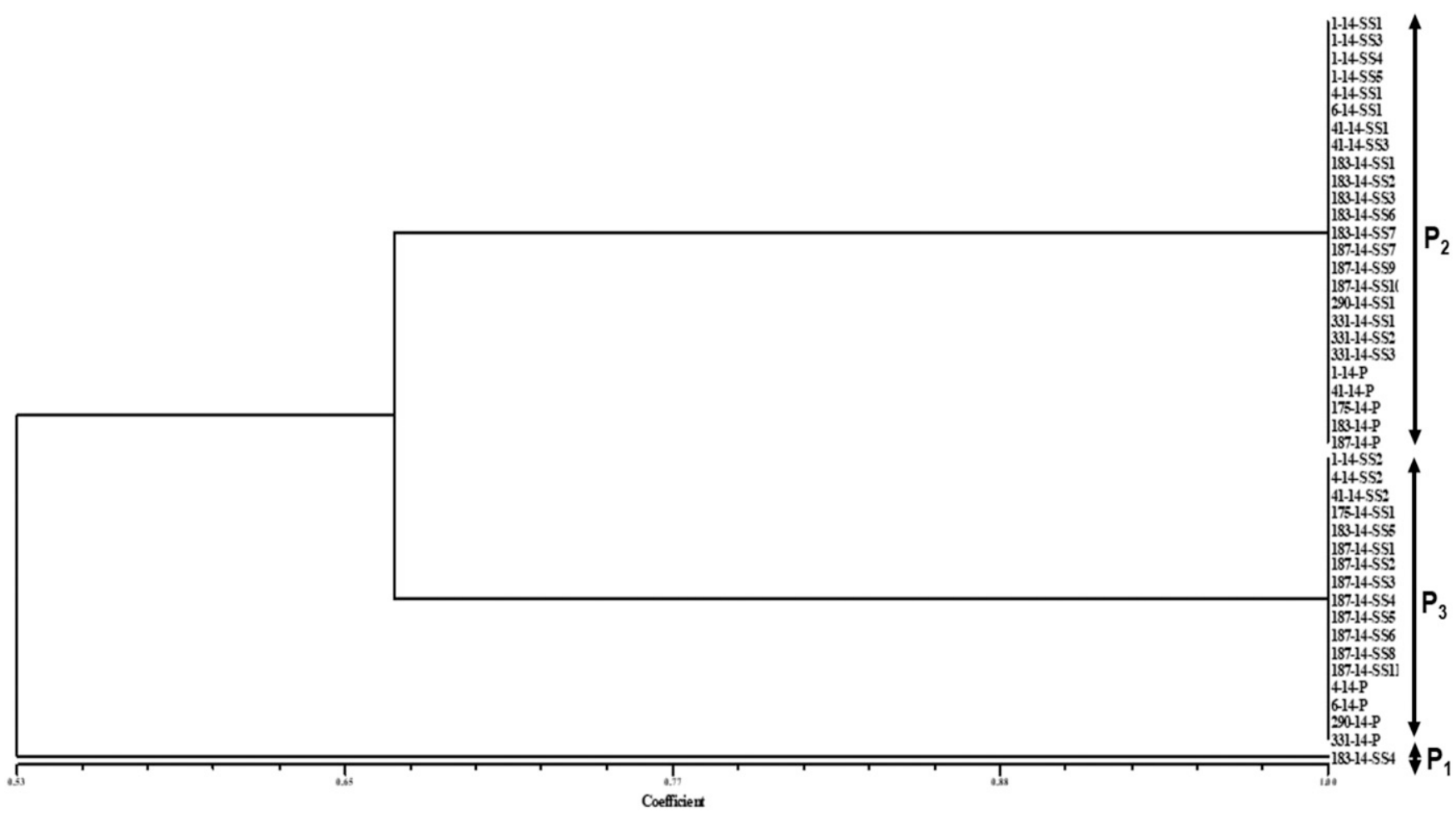

Fig. 2. Pathogenic similarity of Plasmodiophora brassicae isolates on the differential hosts of Somé et al. (1996) based on a threshold index of disease $=50 \%$. The dendrogram was constructed employing the unweighted pair group method with arithmetic means procedure and simple similarity coefficient with NTSys-pc ver. 2.2. Three pathotypes $\left(P_{1}, P_{2}\right.$, and $P_{3}$ ) were identified among the isolates tested, with $P_{2}$ found to be predominant.

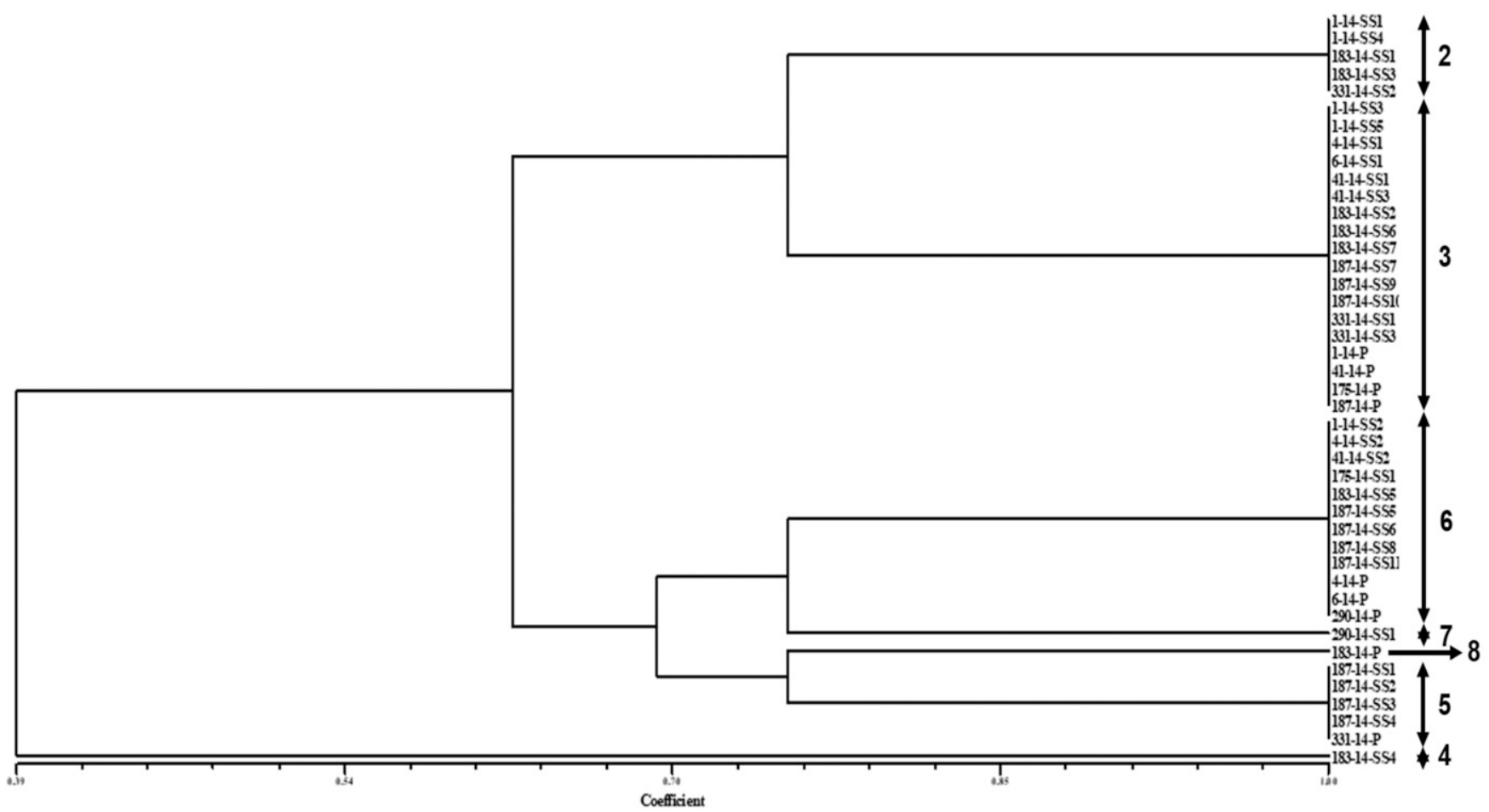

Fig. 3. Pathogenic similarity of Plasmodiophora brassicae isolates on the differential hosts of Williams (1966) based on a threshold index of disease $=50 \%$. The dendrogram was constructed employing the unweighted pair group method with arithmetic means procedure and simple similarity coefficient with NTSys-pc ver. 2.2 . Seven pathotypes $(2,3,4,5,6$, 7 , and 8 ) were identified among the isolates tested, with pathotype 3 found to be predominant. 
IDs. In general, however, the number of isolates classified as virulent on the other hosts increased as the threshold ID was lowered from 50 to $25 \%$. Nevertheless, the number of isolates considered virulent on ECD 06, ECD 08, ECD 09, ECD 13, and Laurentian were similar at the three different thresholds. ECD 02 was resistant to all isolates at all thresholds with the exception of isolate 183-14SS5 when the threshold ID was set to $25 \%$. Only one (2\%) of the isolates (183-14-SS4) was regarded as virulent on ECD 10 at a threshold of $50 \%$ but this increased to $11(26 \%)$ and $22(51 \%)$ of the isolates at 33 and $25 \%$, respectively. Similarly, there was a rise in the number of isolates classified as virulent on ECD 11, Mendel, and $45 \mathrm{H} 29$ as the threshold ID was lowered from 50 to 33 and $25 \%$ (Fig. 5).
The Mantel test indicated significant and strong correlations between virulence matrices generated using threshold IDs of 25, 33, and $50 \%$ on each of the three differential sets (Table 4). The highest correlation (90\%) was found between matrices produced with thresholds of 25 and $33 \%$ on the CCD set. A comparison of associated matrices generated with thresholds of 25 and 33 versus $50 \%$ on the CCD set also showed high correlations ( 81 and $87 \%$, respectively). The lowest but still significant correlation $(51 \%)$ was observed between matrices generated using threshold IDs of 25 and $50 \%$ on the hosts of Williams. On the differentials of Somé et al., a correlation of $57 \%$ was found in pairwise comparisons of the matrix generated with a threshold ID of $25 \%$ versus each of the matrices produced with thresholds of 33 or $50 \%$. A correlation of $74 \%$ was observed between

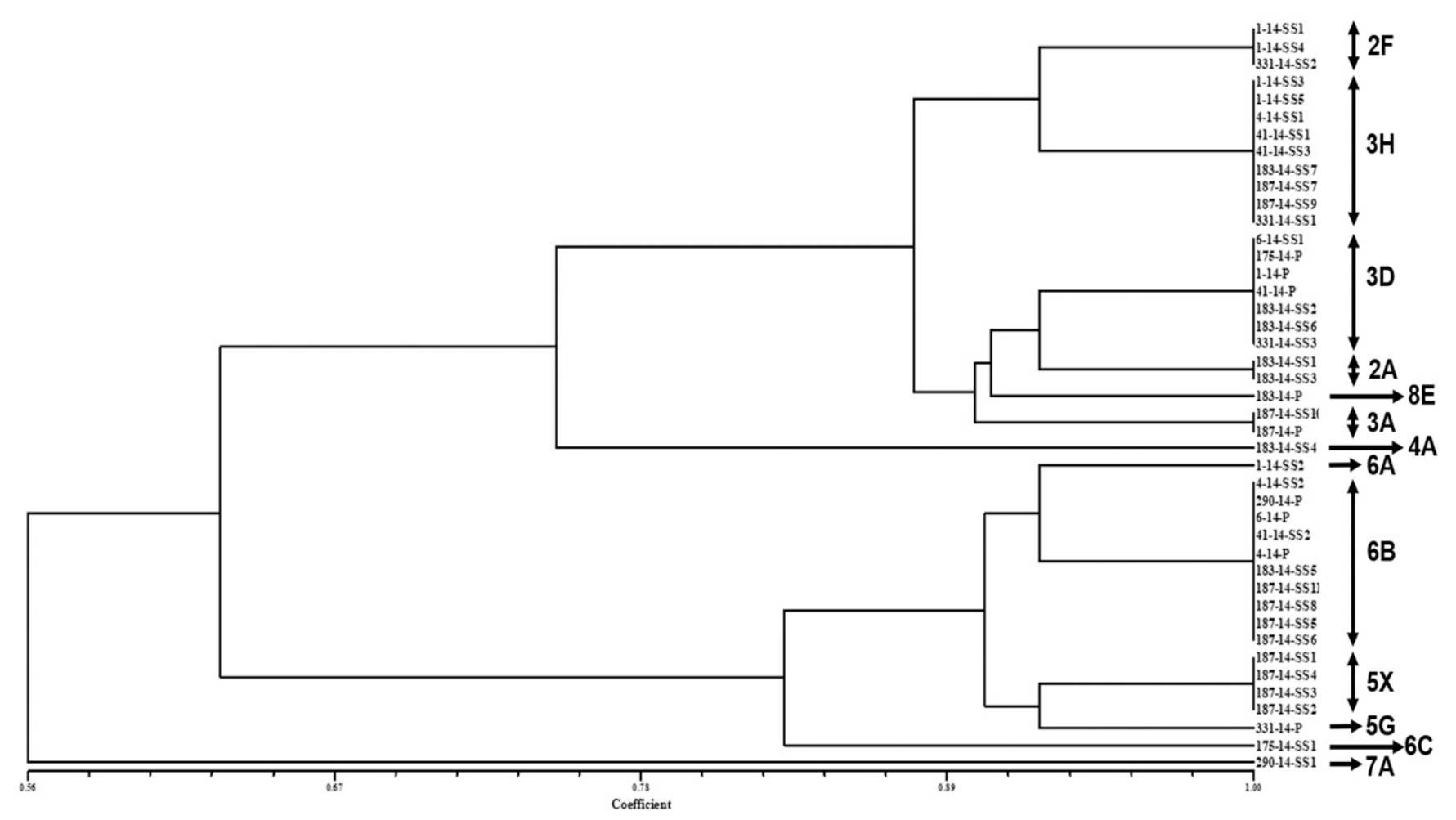

Fig. 4. Pathogenic similarity of Plasmodiophora brassicae isolates on the Canadian Clubroot Differential hosts based on a threshold index of disease $=50 \%$. The dendrogram was constructed employing the unweighted pair group method with arithmetic means procedure and simple similarity coefficient with NTSys-pc ver. 2.2. Thirteen different pathotypes $(2 \mathrm{~A}, 2 \mathrm{~F}, 3 \mathrm{~A}, 3 \mathrm{D}, 3 \mathrm{H}, 4 \mathrm{~A}, 5 \mathrm{G}, 5 \mathrm{X}, 6 \mathrm{~A}, 6 \mathrm{~B}, 6 \mathrm{C}, 7 \mathrm{~A}$, and 8E) were identified, with pathotype $6 \mathrm{~B}$ found to be most common, followed by $3 \mathrm{H}$.

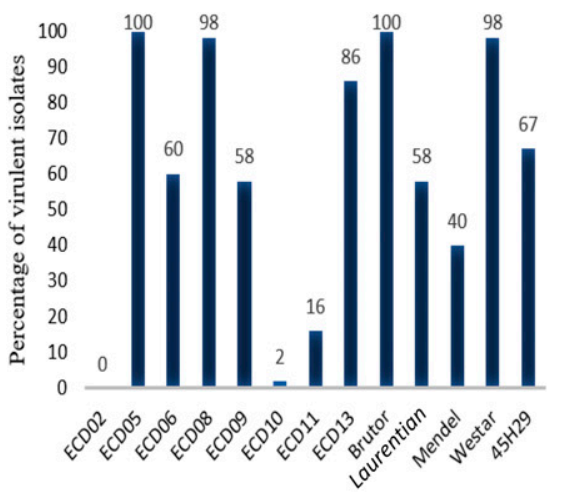

Threshold of $\mathbf{5 0 \%}$

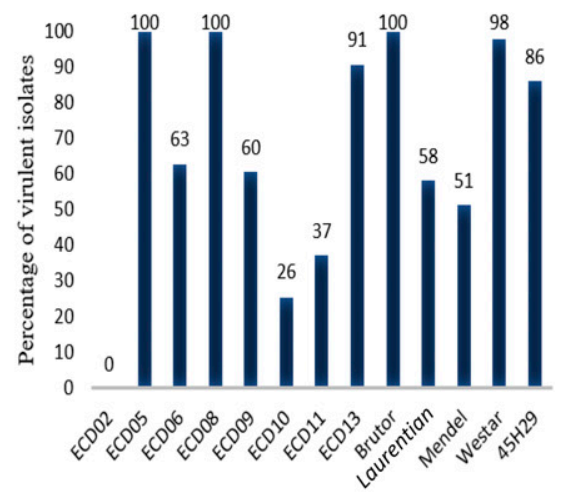

Threshold of $33 \%$

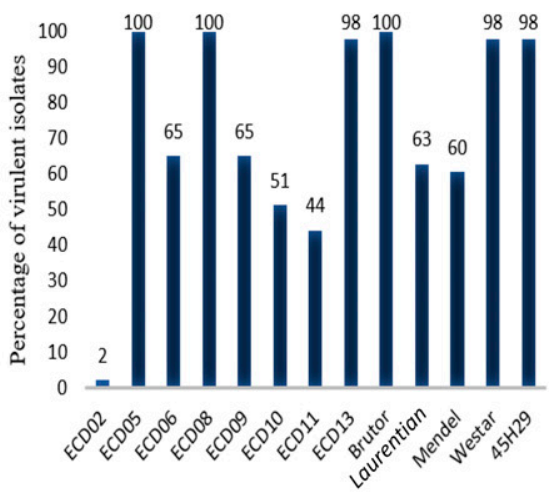

Threshold of $\mathbf{2 5 \%}$

Fig. 5. Percentage of isolates scored as virulent on the 13 host genotypes of the Canadian Clubroot Differential set employing thresholds of 50,33 , and $25 \%$. For each host genotype-pathogen combination, mean indices of disease (IDs) and 95\% confidence intervals (Cl) were calculated. Three thresholds were compared for the classification of resistant and susceptible reactions. These included ID $<50 \%$ (host reaction classified as resistant if the ID $<50 \%$ and the $95 \%$ Cl does not overlap $50 \%$ ) (LeBoldus et al. 2012), ID < 33\% (host reaction classified as resistant if the ID < 33\% and the $95 \% \mathrm{Cl}$ does not overlap $33 \%$ ), and ID < $25 \%$ (host reaction classified as resistant if ID < $25 \%$ and $95 \% \mathrm{Cl}$ does not overlap 25\%) (Somé et al. 1996; LeBoldus et al. 2012). 
matrices generated with threshold IDs of 33 and $50 \%$ on these hosts (Table 4).

Pathotype designations. At a threshold of 50\%, three pathotypes could be distinguished on the differentials of Somé et al.; namely $\mathrm{P}_{1}$, $\mathrm{P}_{2}$, and $\mathrm{P}_{3}$, with $\mathrm{P}_{2}$ representing more than half the isolates. On the system of Williams, seven pathotypes were identified, including pathotypes 2 (5 isolates [12\%]), 3 (18 isolates [42\%]), 4 (1 isolate [2\%]), 5 (5 isolates [12\%]), 6 (12 isolates [28\%]), 7 (1 isolate [2\%]), and 8 (1 isolate [2\%]). The seven Williams pathotypes could be subdivided further into 13 pathotypes with the CCD set. These included pathotypes $2 \mathrm{~A}$ ( 2 isolates [5\%]), 2F (3 isolates [7\%]), 3A (2 isolates [5\%]), 3D (7 isolates [16\%]), 3H (9 isolates [21\%]), 4A (1 isolate [2\%]), 5G (1 isolate [2\%]), 5X (4 isolates [9\%]), 6A (1 isolate [2\%]), 6B (10 isolates [23\%]), 6C (1 isolate [2\%]), 7A (1 isolate [2\%]), and 8E (1 isolate [2\%]).

In most cases, multiple pathotypes were identified from singlespore isolates derived from one field isolate. Pathotypes $\mathrm{P}_{2}, \mathrm{P}_{3} / 2 \mathrm{~F}$, $3 \mathrm{H}$, and $6 \mathrm{~A}$ were recovered from the five single-spore isolates obtained from field isolate 1-14-P, which was classified as pathotype $\mathrm{P}_{2} / 3 \mathrm{D}$ on the systems of Somé et al. and Williams/CCD, respectively. These single-spore isolates shared similar virulence patterns with 114-P on the differential hosts ECD 02, ECD 05, ECD 08, ECD 10, ECD 13, Brutor, Mendel, and Westar. However, although ECD 06, ECD 09, and Laurentian were susceptible to most of the singlespore isolates and the original field isolate, these hosts were resistant to 1-14-SS2. The single-spore isolates 1-14-SS1 and 1-14-SS4 were virulent on ECD 11, which was resistant to the original field isolate. Only the single-spore isolate 1-14-SS2 was virulent on the CR canola $45 \mathrm{H} 29$ such as 1-14-P.

One of two single-spore isolates (4-14-SS2) derived from field isolate 4-14-P shared the same virulence pattern on all 13 differential hosts, retaining the pathotype classifications $\mathrm{P}_{3} / 6 \mathrm{~B}$ on the systems of Somé et al. and Williams/CCD. The other single-spore isolate, 4-14-SS1, gave different reactions on ECD 06, ECD 09, Laurentian, Mendel, and $45 \mathrm{H} 29$, and was designated as pathotype $\mathrm{P}_{2} / 3 \mathrm{H}$. Only one single-spore isolate was derived from field isolate 6-14-P; this single-spore isolate possessed different virulence patterns on the hosts ECD 06, ECD 09, Laurentian, and Mendel relative to its parent. Among the three single-spore isolates derived from field isolate 4114-P, which was virulent on $45 \mathrm{H} 29$ and classified as pathotype $\mathrm{P}_{2} /$ $3 \mathrm{D}$, the single-spore isolates 41-14-SS1 and 41-14-SS3 shared the same virulence pattern on all hosts, with the exception of $45 \mathrm{H} 29$, resulting in a pathotype designation of $\mathrm{P}_{2} / 3 \mathrm{H}$. The single-spore isolate 41-14-SS2 generated distinct reactions on ECD 06, ECD 09, Laurentian, and Mendel relative to the original field isolate and was classified as pathotype $\mathrm{P}_{3} / 6 \mathrm{~B}$. Although the differentials ECD 06, ECD 09, Laurentian, and 45H29 were susceptible to field isolate 175-14-P, they were resistant to 175-14-SS1, the sole single-spore isolate derived from this field isolate.

None of the single-spore isolates derived from the field isolate 183-14-P shared an identical virulence pattern with the parent on all 13 differential hosts. Although 183-14-P was classified as pathotype $\mathrm{P}_{2} / 8 \mathrm{E}$, multiple pathotype classifications were obtained among the single-spore isolates, including $\mathrm{P}_{1}, \mathrm{P}_{2}, \mathrm{P}_{3} / 2 \mathrm{~A}, 3 \mathrm{D}, 3 \mathrm{H}, 4 \mathrm{~A}$, and 6B. Most notably, all single-spore isolates were virulent on ECD 13, which was resistant to the field isolate. On the hosts ECD 02, ECD 05, ECD 08, Brutor, and Westar, the virulence patterns of the single-spore isolates were the same as the original field isolate. The single-spore isolate 183-14-SS4 was virulent on all host genotypes, except ECD 02.

The most single-spore isolates $(n=11)$ were obtained from the field isolate $187-14-\mathrm{P}$, which was classified as $\mathrm{P}_{2} / 3 \mathrm{~A}$. Only one of those single-spore isolates (187-14-SS10), however, shared all three pathotype classifications with 187-14-P. The other single-spore isolates were classified as various pathotypes, including $\mathrm{P}_{2}, \mathrm{P}_{3} / 3 \mathrm{H}, 5 \mathrm{X}$, and 6B. The 11 single-spore isolates had the same virulence patterns as the parent field isolate on the hosts ECD 02, EDC 05, ECD 08, ECD 10, ECD 11, Brutor, and Westar. However, two of the singlespore isolates (187-14-SS7 and 187-14-SS9) were avirulent on the CR canola $45 \mathrm{H} 29$. Laurentian was susceptible to the field isolate
(187-14-P) and three of the single-spore isolates (187-14-SS7, 18714-SS9, and 187-14-SS10). These three single-spore isolates were virulent on ECD 06 and ECD 09, as was the parent field isolate. The differential host ECD 13 was resistant to four single-spore isolates (187-14-SS1, 187-14-SS2, 187-14-SS3, and 187-14-SS4). Contrasting reactions were observed on Mendel in response to inoculation with the isolates 187-14-SS7 and 187-14-SS9.

Only one single-spore isolate (290-14-SS1) was obtained from the field isolate 290-14-P (classified as $\mathrm{P}_{3} / 6 \mathrm{~B}$ ). The single-spore isolate shared the same virulence pattern as 290-14-P on ECD 02, ECD 05, ECD 09, ECD 10, ECD 13, Brutor, and Laurentian but the reactions of ECD 08, ECD 11, Mendel, Westar, and 45H29 were different, resulting in a pathotype classification of $\mathrm{P}_{2} / 7 \mathrm{~A}$ for the single-spore isolate. The field isolate 331-14-P, classified as pathotype $\mathrm{P}_{3} / 5 \mathrm{G}$, yielded single-spore isolates belonging to a variety of pathotypes $\left(\mathrm{P}_{2} / 2 \mathrm{~F}, 3 \mathrm{D}\right.$, and $\left.3 \mathrm{H}\right)$. Although 331-14-P was avirulent on ECD 06, ECD 09, ECD 13, and Laurentian, all single-spore isolates derived from this parent were virulent on these hosts. The CR canola $45 \mathrm{H} 29$ was resistant to two of the single-spore isolates (331-14SS1 and 331-14-SS2) and susceptible to the original field isolate and the third single-spore isolate (331-14-SS3). One single-spore isolate, 331-14-SS2, was virulent on ECD 11. The differentials ECD 02, ECD 05, ECD 08, ECD 10, Brutor, Mendel, and Westar exhibited similar reactions to the field isolate and all three single-spore isolates.

\section{Discussion}

The emergence of $P$. brassicae strains capable of overcoming host resistance represents a significant challenge to the management of clubroot on canola (Strelkov et al. 2016, 2018). An accurate assessment of the pathotype composition of $P$. brassicae populations is a prerequisite for the identification of new and effective sources of genetic resistance. Field isolates can represent heterogeneous mixtures of pathotypes; therefore, the characterization of single-spore isolates is important for such assessments. In the current study, 34 singlespore isolates were obtained from pathogen collections made from $\mathrm{CR}$ canola. The infection rate obtained by inoculation of single resting spores recovered from the various field isolates ranged from 2 to $22 \%$. Resting-spore maturity and viability can vary among field isolates of $P$. brassicae, which may help to explain the variability in these results. Kageyama and Asano (2009) indicated that restingspore populations may be at various stages of maturation and that their ability to germinate is linked to this maturity. In the present study, the average infection rate was $7.6 \%$, which compares favorably with the infection rates that have been reported previously (Buczacki 1977; Diederichsen et al. 2016; Jones et al. 1982b; Manzanares-Dauleux et al. 1994; Scott 1985; Somé et al. 1996; Tinggal and Webster 1981; Voorrips 1996; Xue et al. 2008). The efficacy of any single-spore isolation procedure may depend on the condition of the spore suspension, particularly the percentage of mature and viable spores, as well as technical differences between procedures (Buczacki 1977; Voorrips 1996).

Field isolates of $P$. brassicae are often maintained and propagated on the universally susceptible Chinese cabbage Granaat. It has been

Table 4. Correlation between virulence matrices derived from datasets generated using threshold indices of disease of 25,33 , and $50 \%$ on the differential hosts of the Canadian Clubroot Differential (CCD) set (Strelkov et al. 2018), Williams (1966), and Somé et al. (1996)

\begin{tabular}{lcc}
\hline Differential set & Thresholds $(\%)$ & Correlation $(\boldsymbol{\%})$ \\
\hline CCD & 25 and 33 & 90 \\
& 25 and 50 & 81 \\
\multirow{2}{*}{ Williams } & 33 and 50 & 87 \\
& 25 and 33 & 71 \\
\multirow{2}{*}{ Somé et al. } & 25 and 50 & 51 \\
& 33 and 50 & 66 \\
& 25 and 33 & 57 \\
& 25 and 50 & 57 \\
\hline
\end{tabular}


suggested that all pathotypes represented in one gall will propagate similarly on this line without any obvious change in the pathotype composition of the gall (Buczacki et al. 1975). However, Jones et al. (1982a) and Fähling et al. (2003) stated that, even on a susceptible line, environmental circumstances might encourage a selective multiplication of a subset of all existing pathotypes within a single field isolate. Furthermore, if there is a fitness cost to the pathogen for virulence on a particular source of resistance, it is possible that those virulent isolates will be selected against on a completely susceptible host (Crute et al. 1980; Diederichsen et al. 2009; Dixon 2009b; Montarry et al. 2010). In the current study, to reduce the possibility of changes in pathotype composition or shifts in the virulence of the field isolates, single-spore isolation was carried out directly from the field-collected galls.

To date, the isolation of $P$. brassicae single-spore isolates has been performed with agar- and agarose-based techniques (ManzanaresDauleux et al. 1994; Scott 1985; Somé et al. 1996; Tinggal and Webster 1981) or by using droplets of highly diluted spore suspensions (Buczacki 1977; Voorrips 1996; Xue et al. 2008). There are some difficulties associated with the employment of either of these methods. The need for special equipment and micromanipulative devices to cut and lift the agar or agarose gel pieces containing single spores is one of the disadvantages of agarose-based methods. The fact that standard compound microscopes are designed to capture light emitted from a two-dimensional object, whereas a droplet is a threedimensional (spherical) object with multiple focal planes, is a limitation of the use of droplet suspensions. Evaporation of the droplet and surface tension are additional concerns. The current study combined these two approaches, with some modifications, to simplify the procedure. Small pieces of agarose gel were cut with a scalpel and placed on a microscope slide; then, a highly diluted spore suspension was laid on the center of each gel slice. The use of small pieces of agarose gel, rather than the spread of the spore suspension over the entire surface of an agarose plate, reduced the chances that multiple rather than single spores were obtained, because additional spores could be concealed on the edge of the agarose during the cutting procedure. In addition, because $P$. brassicae resting spores tend to aggregate, the resting-spore suspension included $5 \%$ ( $\mathrm{vol} / \mathrm{vol})$ glycerol, as recommended by Xue et al. (2008).

Several studies suggest that the presence of primary plasmodia or pathogen DNA can be detected beginning 3 days after inoculation (Devos et al. 2005; Ingram and Tommerup 1972; Kageyama and Asano 2009). Hence, seedlings were incubated for $72 \mathrm{~h}$ in darkness before they were transferred to a potting mixture, rather than $48 \mathrm{~h}$ as has often been reported (Somé et al. 1996; Voorrips 1996; Xue et al. 2008). Because temperature significantly influences the germination of the resting spores, incubation of the seedlings was conducted at $23^{\circ} \mathrm{C}$, following reports that the optimum temperature range for infection is 20 to $25^{\circ} \mathrm{C}$ (Ikegami et al. 1981; Wellman 1930).

The occurrence of intermediate and fluctuating host reactions can hinder the study of physiologic specialization in P. brassicae (Jones et al. 1982a; Scott 1985; Strelkov et al. 2006, 2007; Tinggal and Webster 1981; Toxopeus et al. 1986; Xue et al. 2008), and a major aim of single-spore isolation is to obtain genetically homogeneous pathogen inoculum. Nevertheless, in this and earlier studies, intermediate host reactions were still observed following inoculation with single-spore isolates. This may reflect heterogeneity in some of the differential hosts (Jones et al. 1982a; Kuginuki et al. 1999), and suggests that a refined clubroot differential set that includes homozygous inbred lines would be valuable, helping to facilitate understanding of the genetics of resistance in the clubroot pathosystem. In the case of the $B$. oleracea differentials, intermediate disease reactions could reflect the occurrence of polygenic resistance (Crute et al. 1980; Piao et al. 2009). The latter is consistent with the observation in the current study that intermediate IDs most frequently occurred on ECD 11 and ECD 13. It is also worth noting that, although $P$. brassicae inoculum derived from single spores is considered to be genetically homogeneous, this has not been demonstrated by genetic or molecular means. The possibility that heterogeneity could be introduced during propagation of $P$. brassicae (i.e., increasing from one to billions of spores over an infection cycle) cannot be ruled out. For instance, in a study of haploid and diploid yeast populations, Sharp et al. (2018) found that haploids were subject to more single-nucleotide mutations, especially for DNA replicated later in the cell cycle.

Because intermediate host reactions are often observed in response to inoculation with the clubroot pathogen, several threshold IDs have been proposed to discriminate between a resistant and a susceptible response. For example, Somé et al. (1996) used a threshold ID of $25 \%$ when pathotyping field and single-spore isolates from France. In contrast, in a study from Canada, Strelkov et al. (2006) found that most hosts developed IDs from 0 to approximately $45 \%$ and from approximately 65 to $100 \%$, with only a few genotypes exhibiting IDs of 45 to $65 \%$. Hence, they took an ID of $50 \%$ as the threshold between a resistant and susceptible reaction (Strelkov et al. 2006). In the current study, three thresholds $(25,33$, and 50\%) were compared. As expected, the threshold applied influenced the number, type, and frequency of pathotypes identified among the single-spore and field isolates examined. Use of thresholds set at 25 and $33 \%$ resulted in the identification of larger numbers of putative pathotypes, which were often based on small differences in ID. Similar results were reported in an analysis of $P$. brassicae field isolates from the Czech Republic and Poland, when thresholds of 25 and 50\% were compared (Řičařová et al. 2016). Consequently, an advantage of using a 50\% threshold in the current study is that it may be more natural or less arbitrary for the differentiation of the isolates. However, it may not be the most appropriate threshold when screening of genetic resistance for breeding purposes, where presumably the breeders would be looking for highly resistant hosts (IDs $<20$ or $<10 \%$ ).

In the present analysis of field and single-spore isolates from Alberta, the mean IDs for most hosts ranged from 0 to approximately $45 \%$ and from 65 to $100 \%$, although the reactions of ECD 11, ECD 13 , and $45 \mathrm{H} 29$ occasionally fell between 45 and $65 \%$. This was consistent with the earlier report of Strelkov et al. (2006) and, therefore, a threshold ID of $50 \%$ to discriminate between resistant and susceptible host reactions gave the most consistent results. Indeed, most recent studies from Canada have designated reactions as resistant if the ID is $<50 \%$ and the $95 \%$ CI does not overlap $50 \%$ (Al-Daoud et al. 2018; Cao et al. 2020; LeBoldus et al. 2012; Strelkov et al. 2016, 2018), and these were the criteria applied here to classify $P$. brassicae isolates into pathotypes. Nonetheless, similarity matrices were also generated for each differential set and threshold ID (25, 33 , and 50\%). The highest correlation coefficients were observed among the matrices generated on the CCD set, which suggests that the choice of a specific threshold has the least impact on this set compared with the differentials of Williams or Some et al. It may be valuable in the future to compare the genetic structure of isolates with these virulence datasets, to determine which threshold has a higher correlation with the genetic background information.

In all, 13 pathotypes were identified with the CCD set, while 7 and 3 pathotypes were detected on the differentials of Williams and Somé et al., respectively, This confirms a greater differentiating capacity with the CCD relative to the two other systems. Many of the CCD pathotypes reported by Strelkov et al. (2018) from Alberta and other regions of Canada, including pathotypes $3 \mathrm{~A}, 3 \mathrm{D}, 3 \mathrm{H}, 5 \mathrm{G}$, and $8 \mathrm{E}$, also were found in this study. In addition, several novel pathotypes, designated 2A, 4A, 6A, 6B, 6C, and 7A, were recovered among the single-spore isolates (Table 5). These pathotypes may have been newly introduced to these fields, or they may have been present at a low frequency but not detected previously. Indeed, the singlespore isolates were derived from field isolates shown to be a mixture of pathotypes and, therefore, their virulence patterns may have been masked by pathotypes occurring at higher frequencies (Jones et al. $1982 b$ ). Four of the novel pathotypes were virulent on one or both of the CR B. napus cultivars tested ( $45 \mathrm{H} 29$ and Mendel), and likely were selectively increased by the cultivation of CR hosts.

Pathotype 6B (virulent on Mendel and 45H29) and pathotype $3 \mathrm{H}$ (corresponding to the "original" pathotype 3 and avirulent on Mendel and 45H29) were found with almost the same frequency and were predominant in the current study. In contrast, pathotype $3 \mathrm{~A}$, which can overcome resistance and was found with increasing frequency 
among field isolates from Alberta in 2014 to 2016 (Strelkov et al. 2018), was rare. This may reflect the fact that the field isolates used for single-spore isolation in the present study included only one classified as pathotype 3A. Pathotype $2 \mathrm{~F}$ (corresponding to the "original" pathotype 2) (Strelkov et al. 2018) was also identified among the single-spore isolates, as was pathotype $5 \mathrm{X}$. The latter represents the first pathotype identified in Canada that could overcome resistance, although it was not found again in pathogen collections made from 2014 to 2016 (Strelkov et al. 2016, 2018). Interestingly, the four single-spore isolates classified as pathotype $5 \mathrm{X}$ were derived from 187-14-P, which was the field isolate classified as pathotype 3A.

On the hosts of Williams and Somé et al., pathotypes 3 and $\mathrm{P}_{2}$, respectively, were predominant, a finding consistent with previous reports (Cao et al. 2009; Strelkov et al. 2006, 2007; Xue et al. 2008). In addition, several additional pathotypes, as defined on these systems and not previously reported from Canada, also were recovered. These included pathotype $\mathrm{P}_{1}$ (Somé et al. 1996) and pathotypes 4 and 7 (Williams 1966).

As in earlier assessments, more isolates appeared to overcome the resistance in the $\mathrm{CR}$ canola $45 \mathrm{H} 29$ than in the $\mathrm{CR}$ winter oilseed rape Mendel (Strelkov et al. 2018). At a threshold ID of 50\%, 29 of the isolates in the present study were virulent on $45 \mathrm{H} 29$ versus only 17 isolates that were virulent on Mendel. Fredua-Agyeman et al. (2018) suggested that most CR canola cultivars from Canada derive their clubroot resistance from Mendel, which is controlled by a major dominant gene (Diederichsen et al. 2006). Nevertheless, Mendel may also possess additional unmapped resistance genes, which could have been lost during development of the commercial CR cultivars, resulting in increased clubroot susceptibility in some cases (FreduaAgyeman et al. 2018; Strelkov et al. 2018). In addition to the many canola cultivars that appear to possess Mendel-derived resistance, several cultivars have recently been released that are advertised as possessing "second-generation resistance". The nature of secondgeneration resistance has not been disclosed but appears to be distinct from Mendel. It will be important to monitor these new varieties for their performance in P. brassicae-infested fields. Interestingly, the older, open-pollinated canola cultivar Westar, which was reported to be susceptible to all isolates of $P$. brassicae from Canada (Strelkov et al. 2016, 2018), was found to be resistant to one single-spore isolate (290-14-SS1) in the current study.

As previously reported (Cao et al. 2009; Strelkov et al. 2007, 2016, 2018; Xue et al. 2008), ECD 02 was highly resistant to all of the

Table 5. Reaction of the novel pathotypes of Plasmodiophora brassicae found in the current study on the 13 host genotypes of the Canadian Clubroot Differential (CCD) differential set

\begin{tabular}{lcccccc}
\hline Differential sets and hosts & \multicolumn{7}{c}{ Pathotype designations and reactions } \\
\hline Differential sets & & & & & & \\
CCD & $2 \mathrm{~A}$ & $4 \mathrm{~A}$ & $6 \mathrm{~A}$ & $6 \mathrm{~B}$ & $6 \mathrm{C}$ & $7 \mathrm{~A}$ \\
Williams & 2 & 4 & 6 & 6 & 6 & 7 \\
Somé et al. & $\mathrm{P}_{2}$ & $\mathrm{P}_{1}$ & $\mathrm{P}_{3}$ & $\mathrm{P}_{3}$ & $\mathrm{P}_{3}$ & $\mathrm{P}_{2}$ \\
Host genotypes & & & & & & \\
ECD 02 & - & - & - & - & - & - \\
ECD 05 & + & + & + & + & + & + \\
ECD 06 & + & + & - & - & - & + \\
ECD 08 & + & + & + & + & + & - \\
ECD 09 & + & + & - & - & - & - \\
ECD 10 & - & + & - & - & - & - \\
ECD 11 & + & + & - & - & - & + \\
ECD 13 & + & + & + & + & + & + \\
Brutor & + & + & + & + & + & + \\
Laurentian & + & + & - & - & - & - \\
Mendel & - & + & - & + & - & - \\
Westar & + & + & + & + & + & - \\
45H29 & + & + & + & + & - & - \\
\hline
\end{tabular}

a Pathotype designations are based on the systems of the CCD, Williams (1966), and Somé et al. (1996). A plus (+) sign denotes a susceptible host reaction, while a minus (-) sign denotes a resistant reaction. Hosts are classified as resistant if ID $<50 \%$ and the $95 \%$ confidence interval does not overlap 50\% (LeBoldus et al. 2012). isolates tested and developed the lowest IDs among the hosts studied. In earlier studies, the differential ECD 10 was found to be resistant to all field and single-spore isolates of $P$. brassicae from Canada (Cao et al. 2009; Strelkov et al. 2007; Xue et al. 2008), including those recovered from fields with resistance issues (Strelkov et al. 2016, 2018). In the present experiment, however, this host, which has been reported to carry the crrl gene on chromosome A08 (Hasan and Rahman 2016), was found to be moderately susceptible (ID $=59 \%$ ) to the single-spore isolate 183-14-SS4. Hence, although ECD 10 may be an effective source of resistance to many pathotypes of the clubroot pathogen, it does not appear to be universally resistant to Canadian $P$. brassicae populations.

Most of the single-spore isolates examined in this study were obtained from collections made in central Alberta, with only one each from northern (Athabasca) and southern (Newell) Alberta. Therefore, it is difficult to make conclusions regarding the relationship between pathogen virulence patterns and geographic origins. Nevertheless, the single-spore isolates from northern and southern Alberta generated distinct virulence patterns $\left(\mathrm{P}_{3} / 6 \mathrm{C}\right.$ and $\left.\mathrm{P}_{2} / 7 \mathrm{~A}\right)$ relative to those from the heart of the clubroot outbreak in the central part of the province. Although the amount of data is limited, these findings are consistent with earlier studies, which suggested that field isolates or populations from southern Alberta (Cao et al. 2009) or from northern and southern Alberta (Strelkov et al. 2018) tended to have distinct virulence patterns relative to those from central Alberta.

The results of the current study indicate significant diversity in the virulence of $P$. brassicae single-spore and field isolates from Alberta, which was identified most clearly with the CCD set. The identification of multiple new pathotypes underscores the need for ongoing monitoring of this pathogen in western Canada. The collection of characterized single-spore isolates resulting from this work may serve as a reference and be useful in breeding for clubroot resistance. It could also be of interest in studies of $P$. brassicae biology and evolution. Genetic characterization of this collection using wholegenome sequencing may also provide new insights into pathotype biology and relationships.

\section{Acknowledgments}

We thank Y. Aigu (University of Alberta) for help in preparing the map, as well as summer students and technical personnel for their assistance with the experiments over the course of the study.

\section{Literature Cited}

Akhavan, A., Turkington, T. K., Askarian, H., Tekauz, A., Xi, K., Tucker, J. R., Kutcher, H. R., and Strelkov, S. E. 2016. Virulence of Pyrenophora teres populations in western Canada. Can. J. Plant Pathol. 38:183-196.

Al-Daoud, F., Moran, M., Gossen, B., and McDonald, M. R. 2018. First report of clubroot (Plasmodiophora brassicae) on canola in Ontario. Can. J. Plant Pathol. 40:96-99.

Ayers, G. W. 1957. Races of Plasmodiophora brassicae. Can. J. Bot. 35:923-932.

Buczacki, S. T. 1977. Root infections from single resting spores of Plasmodiophora brassicae. Trans. Br. Mycol. Soc. 69:328-329.

Buczacki, S. T., Toxopeus, H., Mattusch, P., Johnston, T. D., Dixon, G. R., and Hobolth, G. R. 1975. Study of physiological specialization in Plasmodiophora brassicae: Proposals for attempted rationalisation through an international approach. Trans. Br. Mycol. Soc. 65:295-303.

Cao, T., Manolii, V. P., Hwang, S. F., Howard, R. J., and Strelkov, S. E. 2009. Virulence and spread of Plasmodiophora brassicae [clubroot] in Alberta, Canada. Can. J. Plant Pathol. 31:321-329.

Cao, T., Manolii, V. P., Zhou, Q., Hwang, S. F., and Strelkov, S. E. 2020. Effect of canola (Brassica napus) cultivar rotation on Plasmodiophora brassicae pathotype composition. Can. J. Plant Sci. 100:218-225.

Crute, I. R., Gray, A. R., Crisp, P., and Buczacki, S. T. 1980. Variation in Plasmodiophora brassicae and resistance to clubroot disease in Brassicas and allied crops-A critical review. Plant Breed. Abstr. 50:91-104.

Devos, S., Vissenberg, K., Verbelen, J. P., and Prinsen, E. 2005. Infection of Chinese cabbage by Plasmodiophora brassicae leads to a stimulation of plant growth: Impacts on cell wall metabolism and hormone balance. New Phytol. 166:241-250.

Diederichsen, E., Beckmann, J., Schöndelmeier, J., and Dreyer, F. 2006. Genetics of clubroot resistance in Brassica napus 'Mendel'. Acta Hortic. 706:307-312.

Diederichsen, E., Frauen, M., Linders, E. G. A., Hatakeyama, K., and Hirai, M. 2009. Status and perspectives of clubroot resistance breeding in crucifer crops. J. Plant Growth Regul. 28:265-281. 
Diederichsen, E., Wagenblatt, B., and Schallehn, V. 2016. Production of pure genotype isolates of Plasmodiophora brassicae Wor. comparison of inoculations with root hairs containing single sporangiosori or with single resting spores. Eur. J. Plant Pathol. 145:621-627.

Dixon, G. R. 2009a. The occurrence and economic impact of Plasmodiophora brassicae and clubroot disease. J. Plant Growth Regul. 28:194-202.

Dixon, G. R. 2009b. Plasmodiophora brassicae in its environment. J. Plant Growth Regul. 28:212-228.

Fähling, M., Graf, H., and Siemens, J. 2003. Pathotype Separation of Plasmodiophora brassicae by the Host Plant. J. Phytopathol. 151:425-430.

Fredua-Agyeman, R., Hwang, S. F., Strelkov, S. E., Zhou, Q., and Feinde, D. 2018. Potential loss of clubroot resistance genes from donor parent Brassica rapa subsp. rapifera (ECD 04) during doubled haploid production. Plant Pathol. 67:892-901.

Hasan, M. J., and Rahman, H. 2016. Genetics and molecular mapping of resistance to Plasmodiophora brassicae pathotypes 2, 3, 5, 6, and 8 in rutabaga (Brassica napus var. napobrassica). Genome 59:805-815.

Hirai, M. 2006. Genetic analysis of clubroot resistance in Brassica crops. Breed. Sci. 56:223-229.

Horiuchi, S., and Hori, M. 1980. A simple greenhouse technique for obtaining high levels of clubroot incidence. Bull. Chugoku Natl. Agric. Exp. Stn. Ser. E. (Environ. Div.). 17:33-55.

Howard, R. J., Strelkov, S. E., and Harding, M. W. 2010. Clubroot of cruciferous crops-new perspectives on an old disease. Can. J. Plant Pathol. 32:43-57.

Ikegami, H., Ito, T., Imuro, Y., and Naiki, T. 1981. Growth of Plasmodiophora brassicae in the root and callus of Chinese cabbage. Pages 81-90 in: Chinese Cabbage. N. S. Talekar and T. D. Griggs, eds. Asian Vegetable Research and Development Center, Taiwan.

Ingram, D. S., and Tommerup, C. 1972. The life history of Plasmodiophora brassicae Woron. Proc. R. Soc. Lond. Ser. B. 180:103-112.

Jones, D. R., Ingram, D. S., and Dixon, G. R. 1982a. Factors affecting tests for differential pathogenicity in populations of Plasmodiophora brassicae. Plant Pathol. 31:229-238.

Jones, D. R., Ingram, D. S., and Dixon, G. R. 1982b. Characterization of isolates derived from single resting spores of Plasmodiophora brassicae and studies of their interaction. Plant Pathol. 31:239-246.

Kageyama, K., and Asano, T. 2009. Life cycle of Plasmodiophora brassicae. J. Plant Growth Regul. 28:203-211.

Karling, J. S. 1968. The Plasmodiophorales. Hafner Publishing Company Inc., New York, NY, U.S.A.

Kuginuki, Y., Hiroaki, Y., and Hirai, M. 1999. Variation in virulence of Plasmodiophora brassicae in Japan tested with clubroot-resistant cultivars of Chinese cabbage (Brassica rapa L. spp. pekinensis). Eur. J. Plant Pathol. 105:327-332.

LeBoldus, J. M., Manolii, V. P., Turkington, T. K., and Strelkov, S. E. 2012. Adaptation to Brassica host genotypes by a single-spore isolate and population of Plasmodiophora brassicae (clubroot). Plant Dis. 96:833-838.

Manzanares-Dauleux, M. J., Laurens, F., Baron, F., and Thomas, G. 1994. Production of single-spore isolates of Plasmodiophora brassicae. Cruciferae Newsl. 16:132-133.

Montarry, J., Hamelin, F. M., Glais, I., Corbière, R., and Andrivon, D. 2010. Fitness costs associated with unnecessary virulence factors and life history traits: Evolutionary insights from the potato late blight pathogen Phytophthora infestans. BMC Evol. Biol. 10:283.

Peng, G., Falk, K. C., Gugel, R. K., Franke, C., Yu, F., James, B., Strelkov, S. E., Hwang, S. F., and McGregor, L. 2014. Sources of resistance to Plasmodiophora brassicae (clubroot) pathotypes virulent on canola. Can. J. Plant Pathol. 36:89-99.

Piao, Z., Ramchiary, N., and Lim, Y. P. 2009. Genetics of clubroot resistance in Brassica species. J. Plant Growth Regul. 28:252-264.
Rempel, C. B., Hutton, S. N., and Jurke, C. J. 2014. Clubroot and the importance of canola in Canada. Can. J. Plant Pathol. 36:19-26.

Řičařová, V., Kaczmarek, J., Strelkov, S. E., Kazda, J., Lueders, W., Rysanek, P., Manolii, V. P., and Jedryczka, M. 2016. Pathotypes of Plasmodiophora brassicae causing damage to oilseed rape in the Czech Republic and Poland. Eur. J. Plant Pathol. 145:559-572.

Rohlf, F. J. 2009. NTSys-pc: Numerical Taxonomy and Multivariate Analysis System, version 2.20. Applied Biostatistics, New York, NY, U.S.A.

Scott, E. S. 1985. Production and characterization of single-spore isolates of Plasmodiophora brassicae. Plant Pathol. 34:287-292.

Sharp, N. P., Sandell, L., Jamesa, C. G., and Ottoa, S. P. 2018. The genome-wide rate and spectrum of spontaneous mutations differ between haploid and diploid yeast. Proc. Natl. Acad. Sci. USA 115:E5046-E5055.

Somé, A., Manzanares, M. J., Laurens, F., Baron, F., Thomas, G., and Rouxel, F. 1996. Variation for virulence on Brassica napus L. amongst Plasmodiophora brassicae collections from France and derived single-spore isolates. Plant Pathol. 45:432-439.

Strelkov, S. E., and Hwang, S. F. 2014. Clubroot in the Canadian canola crop: 10 Years into the outbreak. Can. J. Plant Pathol. 36:27-36.

Strelkov, S. E., Hwang, S. F., Manolii, V. P., Cao, T., and Feindel, D. 2016. Emergence of new virulence phenotypes of Plasmodiophora brassicae on canola (Brassica napus) in Alberta, Canada. Eur. J. Plant Pathol. 145: 517-529.

Strelkov, S. E., Hwang, S. F., Manolii, V. P., Cao, T., Fredua-Agyeman, R., Harding, M. W., Peng, G., Gossen, B. D., McDonald, M. R., and Feindel, D. 2018. Virulence and pathotype classification of Plasmodiophora brassicae populations collected from clubroot resistant canola (Brassica napus) in Canada. Can. J. Plant Pathol. 40:284-298.

Strelkov, S. E., Manolii, V. P., Cao, T., Xue, S., and Hwang, S. F. 2007. Pathotype Classification of Plasmodiophora brassicae and its Occurrence in Brassica napus in Alberta, Canada. J. Phytopathol. 155:706-712.

Strelkov, S. E., Manolii, V. P., Harding, M. W., Hwang, S. F., Fei, W., Rong, S., Burke, D. A., Pugh, C. A., Nielsen, J. M., Barnes, A., Jacobsen, C., Vadnais, M., and Feindel, D. 2015. The spread of Clubroot on canola in Alberta in 2014. Can. Plant Dis. Surv. 95:155-158.

Strelkov, S. E., Manolii, V. P., Lageyre, J., Hwang, S. F., Harding, M. W., and Daniels, G. C. 2019. Occurrence and spread of clubroot on canola in Alberta in 2018. Can. Plant Dis. Surv. 99:160-163.

Strelkov, S. E., Tewari, J. P., and Smith-Degenhardt, E. 2006. Characterization of Plasmodiophora brassicae populations form Alberta, Canada. Can. J. Plant Pathol. 28:467-474.

Tewari, J. P., Strelkov, S. E., Orchard, D., Hartman, M., Lange, R. M., and Turkington, T. K. 2005. Identification of clubroot of crucifers on canola (Brassica napus) in Alberta. Can. J. Plant Pathol. 27:143-144.

Tinggal, S. H., and Webster, J. 1981. Technique for single spore infection by Plasmodiophora brassicae. Trans. Br. Mycol. Soc. 76:187-190.

Toxopeus, H., Dixon, G. R., and Mattusch, P. 1986. Physiologic specialization in Plasmodiophora brassicae: An analysis by international experimentation Trans. Br. Mycol. Soc. 87:279-287.

Voorrips, R. E. 1995. Plasmodiophora brassicae: Aspects of pathogenesis and resistance in Brassica oleracea. Euphytica 83:139-146.

Voorrips, R. E. 1996. Production, characterization and interaction of single-spore isolates of Plasmodiophora brassicae. Eur. J. Plant Pathol. 102:377-383.

Wellman, F. L. 1930. Clubroot of Crucifers. U.S. Dep. Agric. Technol. Bull. 18

Williams, P. H. 1966. A system for the determination of races of Plasmodiophora brassicae that infect cabbage and rutabaga. Phytopathology 56:624-626.

Xue, S., Cao, T., Howard, R. J., Hwang, S. F., and Strelkov, S. E. 2008. Isolation and variation in virulence of single-spore isolates of Plasmodiophora brassicae from Canada. Plant Dis. 92:456-462. 